\title{
Personality Traits and Misdemeanor of High School Students
}

\author{
Josefa Darling G. Sombero \\ Don Bosco Technical Institute-Victorias, Victorias City, Philippines \\ somberojosefadarling@gmail.com \\ https://orcid.org/0000-0002-3681-6883
}

\begin{abstract}
Distinctive personality traits account for every person, who they are, and how they behave. This study reported the personality traits and extent of misdemeanor of high school students. Additionally, the relationship between personality traits and misdemeanor in demographic variables was also explored. Using descriptive-correlational research designs, 100 respondents who were identified with misdemeanor cases provided data for this study. Using frequency count, mean, and Chi-square in analyzing the results, findings of the study revealed an average level of personality traits and a moderate extent of misdemeanor. Alcohol, school misconduct, and vandalism were found as salient misdemeanor acts among respondents. Furthermore, both indirect and direct salient factors attributed to personality traits and misdemeanor were influential to students. Moreover, indirect and direct sources could predict personality traits and misdemeanor among demographic variables. Intervention program that motivates positive attitude and discipline should be established to manage and cope with behavioral problems.
\end{abstract}

Keywords: Guidance and Counseling, Personality Traits, Misdemeanor, Descriptive-Correlational design, Negros Occidental, Philippines 